\title{
EDUCATIONAL GAME "P3K-KIDS" PERMAINAN EDUKASI PERTOLONGAN PERTAMA PADA KECELAKAAN BERBASIS ANDROID MENGGUNAKAN IMPLEMENTASI SHUFFLE RANDOM
}

\author{
Pajar Pahrudin $^{1)}$, Nursobah ${ }^{2)}$, Heny Pratiwi ${ }^{3)}$, dan Syamsuddin Mallala ${ }^{4)}$ \\ ${ }^{1,4}$ Sistem Informasi, STMIK Widya Cipta Dharma \\ ${ }^{2,3}$ Teknik Informatika, STMIK Widya Cipta Dharma \\ 1,2,3,4 Jl. M. Yamin No.25, Samarinda, 75123 \\ E-mail : pajar@wicida.ac.id ${ }^{1)}$, nursobah@wicida.ac.id ${ }^{2)}$, henypratiwi@wicida.ac.id ${ }^{3)}$, mallala_s@yahoo.co.id ${ }^{4)}$
}

\begin{abstract}
ABSTRAK
Educational game "P3K-Kids" merupakan edugame yang dibangun untuk proses pembelajaran pada anak usia 8 sampai dengan 9 tahun, edugame ini dibangun agar anak - anak dapat mengetahui bagaimana cara menangani Pertolongan Pertama Pada Kecelakaan (P3K) pada saat mereka bermain. Pada penelitian membangun edugame ini diterapkan algoroitma pengacakan posisi dengan shuffle random, dengan tujuan mengacak tantangan mengobati pasien setiap levelnya. Game dibangun menggunakan desain storyboard dan struktur hybrid dan bagan alir Unified Modeling Language (UML) dan menggunakan software SwishMax4, edugame yang dibangun dapat dijalankan pada smartphone android. Dari hasil implementasi dapat disimpulkan bahwa dengan edugame yang dapat mempermudah proses belajar dan dapat memberi pengetahuan tentang cara melakukan pertolongan pertama pada kecelakaan.
\end{abstract}

Kata Kunci: Edugame, Pertolongan Pertama Pada Kecelakaan, Shuffle random, SwishMax 4, Storyboard

\section{PENDAHULUAN}

Edugame (Educational game) adalah salah satu implementasi bidang ilmu komputer yang perkembangannya sudah sangat pesat (Squire,2011). Edugame juga merupakan bentuk aplikasi yang edukatif, artinya dapat dijadikan sebagai media pembelajaran dimana prosesnya dilakukan dengan konsep belajar sambil bermain(Hurd dan Jenuings, 2009).

Informasi pembelajaran yang disajikan dalam bentuk buku atau pembelajaran konvesional terkadang membuat seseorang kurang tertarik, karena media pembelajaran yang ditampilkan oleh buku hanya berupa teks dan pada tampilan isi buku yang tidak dapat divisualisasikan sehingga tampilannya membosankan (tidak bergerak, hitam putih), hal ini menyebabkan seorang merasa jenuh dan minat belajar pun akhirnya berkurang, hal ini telah banyak dipaparkan dari beberapa hasil penelitian (Chee, 2018).

Pendidikan tentang pertolongan pertama pada kecelakaan sendiri menjadi ketersampingkan di era teknologi ini (Kristanto,dkk, 2016). Pengetahuan anakanak modern akan $\mathrm{P} 3 \mathrm{~K}$ cenderung tidak ada atas tersitanya aktfitas mereka dengan bermain permainan smartphone dari pengembang luar negeri. Hadirnya edugame adalah salah satu solusi yang dapat menyisipkan pengetahuan dan pembelajaran akan pertolongan pertama pada kecelakaan. Mengajak anakanak untuk tetap belajar, tetapi dalam bentuk permainan.

Menerapkan permainan edukasi (edugame) sebagai media pembelajaran dapat melahirkan suasana baru yang menyenangkan dalam proses belajar. Gambar dan suara yang muncul membuat proses belajar tidak membosankan (Vos, dkk, 2018). Oleh sebab itu, dilakukan penelitian membangun Edugame "First Aid Care", sebuah permainan yang mengajarkan bagaimana cara memberikan pertolongan pertama pada kecelakaan.

Permainan yang dibangun berjenis drag and drop game yang dirancang untuk mengasah ingat. Pemain dapat menggunakan alat - alat P3K yang tersedia pada scene permainan untuk memberikan penanganan pertolongan pertama kepada korban kecelakaan.

Dalam beberapa penelitian pengembangan edugame yang sama (Ekaprasetia,dkk, 2018; Liu,dkk, 2017), memberikan pembelajaran tentang pertolongan pertama pada kecelakaan. Jenis - jenis cedera dan soal-soal permainan yang disajikan bersifat monoton atau tetap, hal ini akan membuat permainan tampak membosankan (Chee, 2018). Maka dilakukan teknik pengacakan shuffle random untuk mengacak posisi scene pertolongan pertama pada pasien untuk berbagai macam cedera, dengan tujuan membuat permainan yang tidak statis dan membosankan.

Shuffle random adalah pengacakan urutan indeks dari sebuah record atau array (Andrea, 2013). Pengacakan ini diibaratkan pengocokan pada dek kartu, dimana semua kartu dikocok sehingga susunannya teracak (Andrea, 2015). Teknik inilah yang akan diterapkan pada teknik pengacakan susunan tantangan pertolongan pertama pada berbagai macam cedera di game ini. Teknik yang sama juga pernah diterapkan pada game edukasi manajemen waktu yang dilakukan Yusnita,dkk (2017)..

Harapan penelitian dibangunnya "P3K-Kids" dapat menjadi permainan edukasi pertolongan pertama pada 
kecelakaan yang asyik, mendidik dan tidak akan membosankan dari sisi gameplaynya. Dengan teknik pengacakan shuffle untuk membuat tantangan mengobati pasien berubah-ubah dan tidak monoton.

\section{RUANG LINGKUP PENELITIAN}

Permasalahan difokuskan pada :

1. Edugame ini belajar dan bermain Pertolongan Pertama Pada Kecelakaan (P3K).

2. Edugame ini memiliki permainan yang terdiri dari 5 level.

3. Edugame ini ditujukan bagi anak-anak usia 8 sampai 9 tahun.

4. Edugame ini dibuat dengan aplikasi SwishMax4.

5. Algoritma yang digunakan pada permainan ini yaitu algoritma logika pengacakan posisi objek (shuffle random) yang berfungsi untuk mengacak soal atau objek.

6. Edugame ini yang bersifat single user player dan game offline.

7. Edugame ini dapat di jalankan pada smartphone Android minimal versi 4.0 (Ice Cream Sandwich).

\section{BAHAN DAN METODE}

Adapun bahan dan metode yang gunakan dalam membangun pembelajaran ini yaitu:

\subsection{Shuffle Random}

Menurut Andrea (2015), Shuffle random adalah pengacakan urutan indeks dari sebuah record atau array. Pengacakan ini diibaratkan pengocokan pada dek kartu, dimana semua kartu dikocok sehingga susunannya teracak. Contoh lain misalkan A adalah array $5 \times 1, \mathrm{~A}=$ [ $\left.\begin{array}{lllll}1 & 2 & 3 & 4 & 5\end{array}\right]$ maka proses shuffle random akan mengacak susunan indek dari array A menjadi $\mathrm{A}_{1}=\left[\begin{array}{lllll}5 & 1 & 3 & 2 & 4\end{array}\right]$ ataupun menjadi susunan array yang lain. Dalam bahasa pemrograman fungsi shuffle random tidak hanya dapat mengacak angka, tetapi juga dapat mengacak array string ataupun campuran string dan angka. Untuk menerapkan pengacakan posisi gambar dengan sistem shuffle random dilakukan dengan beberapa tahap berikut ini :

1. Menentukan jumlah pasangan gambar

Awal dari penerapan yaitu menentukan jumlah puzzle pasangan gambar dan menyusunnya layaknya sebuah matrik seperti pada gambar 1.

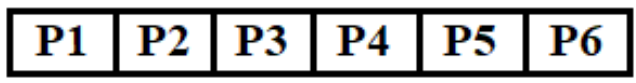

\section{Gambar 1. Matrik 6 × 1 Permainan puzzle penanganan $(P)$ yang belum teracak}

Pada tahap ini dilakukan deklarasi nilai array seperti pada contoh script dibawah ini :

$A=$ new Array $(1,2,3,4,5,6)$

Dimana nilai indek array yang pertama (indeks ke-0) adalah 0 , dan indeks terakhir adalah 5 .
2. Menyimpan setiap koordinat $x$ dan $y$ dari setiap puzzle gambar

Setiap objek gambar atau shape dalam project board permainan pasti memiliki koordinat $x$ dan $y$ seperti pada gambar 2 .

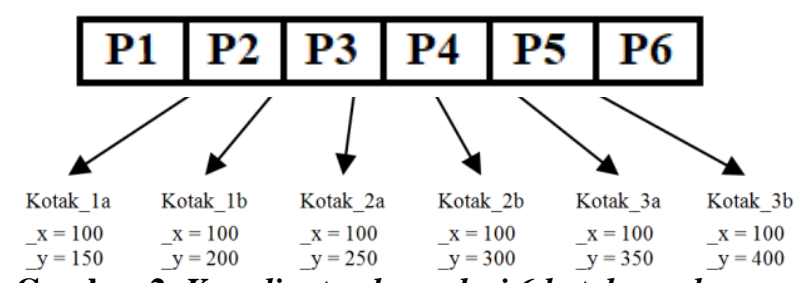

Gambar 2. Koordinat $x$ dan y dari 6 kotak gambar

Pada tahap ini keenam koordinat kotak gambar di catat dalam sebuah prosedur

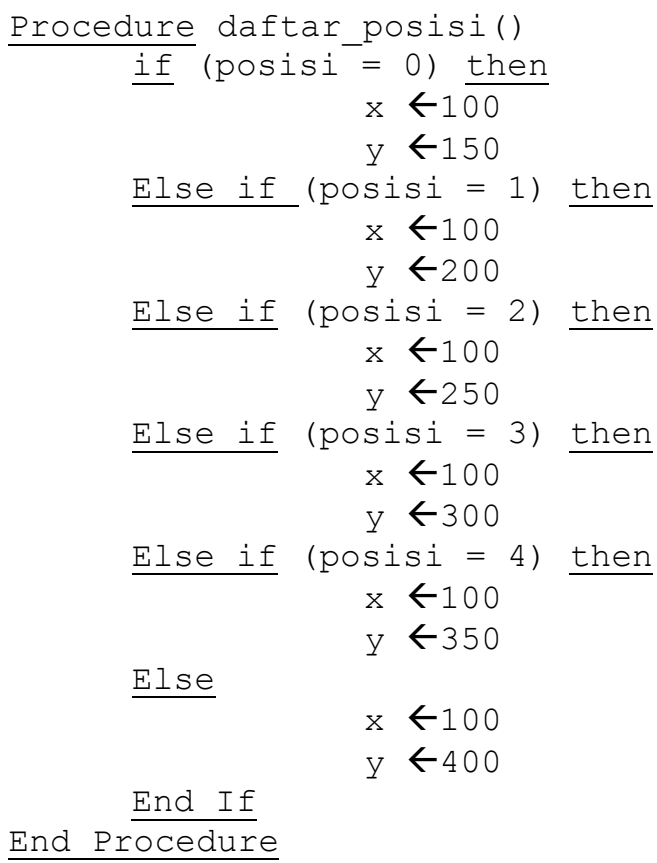

3. Pengkodean pengacakan posisi

Tahap terakhir adalah penggunaan fungsi shuffle random, serta pengacakan posisi koordinat dari setiap kotak puzzle gambar sesuai script pengacakan berikut ini :

$$
\text { posisi } \leftarrow \text { random.shuffle }(A)
$$

sehingga susunan matrik dapat teracak seperti gambar 3.

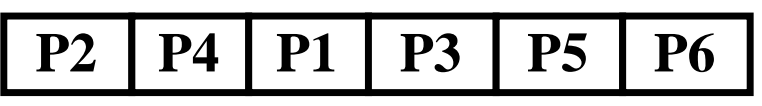

Gambar 3. Matrik $6 \times 1$ Permainan Puzzle penanganan $(P)$ yang telah teracak 


\subsection{Tahapan Pengembangan Multimedia}

metodologi pengembangan multimedia terdiri dari enam tahap, yaitu concept (pengonsepan), design (pendesainan), meterial collecting (pengumpulan materi), assembly (pembuatan), testing (pengujian), dan distribution (pendistribusian). Keenam tahap ini tidak dapat bertukar posisi. Meskipun begitu, tahap concept memang harus menjadi hal yang pertama kali dikerjakan (Agarwal, 2010)

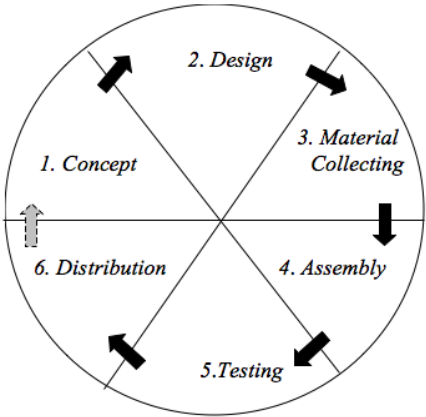

\section{Gambar 4. Tahapan Pengembangan Multimedia}

Tahapan Pengembangan Multimedia pada gambar 4 meliputi :

\section{Concept ( Konsep )}

"Edugame P3K-Kids menggunakan implementasi algoritma shuffle random" adalah sebuah permainan berbasis multimedia yang bertujuan untuk memperkenalkan pertolongan pertama pada kecelakaan yang memberikan manfaat pembelajaran yang interaktif bagi semua kalangan, rileks dan mudah dipelajari ataupun dimainkan oleh pemainnya. Permainan ini memiliki aturan permainan yang sederhana dan menampilkan konten yang dirancang penggunanya untuk anak usia 8 sampai dengan 9 tahun.

\section{Design ( Desain)}

Desain merupakan tahap kedua setelah menentukan konsep permainan, dalam pembuatan "P3KKids" ini semua desain di mulai dari perancangan menggunakan Unified Modeling Language (UML). Terdapat tiga diagram yang digunakan pada sistem ini yaitu Use Case Diagram, Activity Diagram, dan Sequence Diagram sampai dengan perancangan.

\section{Material Collecting (Pengumpulan Bahan}

Pengumpulan bahan merupakan tahap ketiga setelah menentukan desain game, bahan yang digunakan untuk mendukung dalam pembuatan permainan "P3KKids".

\section{Assembly ( Pembuatan )}

Tahapan pembuatan merupakan tahap pembuatan edugame P3K-Kids, Dimana seluruh objek multimedia dibuat berdasarkan bagan alir UML (Unified Modeling Language) dan storyboard yang berasal dari tahap desain dan bahan multimedia yang sudah ditentukan. Tahap ini software yang digunakan adalah Adobe Photoshop CS6 dan SwishMax 4.

5. $\quad$ Testing (Tes)

Testing sistem dilakukan untuk memeriksa kekompakan antar komponen sistem yang diimplementasikan. Tujuan dari pengujian ini adalah untuk menjamin bahwa aplikasi yang sudah di bangun memiliki fungsi yang sesuai dengan yang telah ditentukan.

\section{Distributtion (Distribusi)}

Pada tahapan ini pembuatan Edugame "P3K-Kids" akan dikemas menjadi edugame. Tahap distribusi juga merupakan tahap evaluasi terhadap suatu produk multimedia, diharapkan akan dapat dikembangkan dalam bentuk sistem multimedia yang lebih baik di kemudian hari. Pada tahapan ini pembuatan Edugame "P3K-Kids" di kemas menjadi suatu aplikasi yang dapat dimainkan untuk semua kalangan khususnya yang berusia 8 sampai dengan 9 tahun sebagai alternatif sistem pembelajaran yang efektif dan memberikan pengetahuan lebih bagi pengguna.

\section{RANCANGAN APLIKASI}

Dalam konsep dan perancangan disini menggunakan alat bantu perancangan Storyboard dan bagan alir UML (Unified Modeling Language) pada Edugame "P3KKids" ini sangat cocok sekali diterapkan, karena perancangan menggunakan alat bantu perancangan Storyboard dan UML (Unified Modeling Language) lebih mudah untuk pembuatan aplikasi ada 3 (tiga) macam diagram yang digunakan dalam UML ini yaitu Use case diagram, Activity Diagram dan Sequence Diagram

1. Rancangan Menu Utama pada Edugame "P3K-Kids" Pertolongan Pertama Pada Kecelakaan untuk anak.

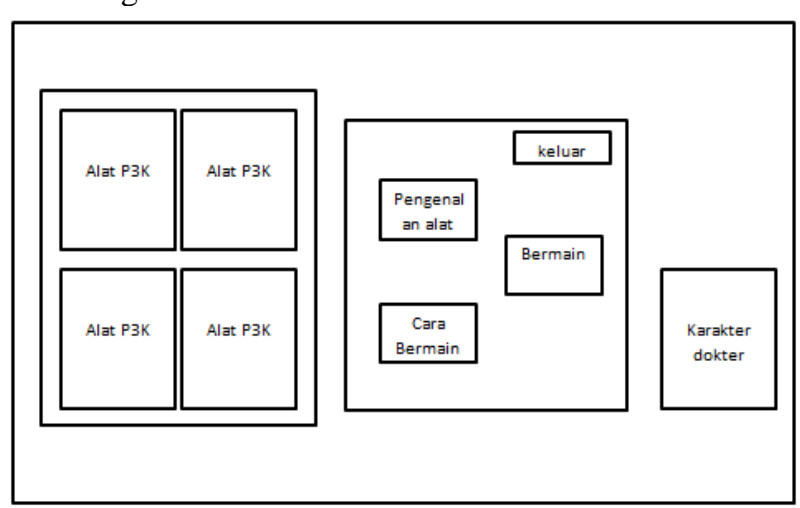

Gambar 5. Menu Utama 
2. Rancangan Pengenalan Alat $\mathrm{P} 3 \mathrm{~K}$ pada Edugame "P3K-Kids"

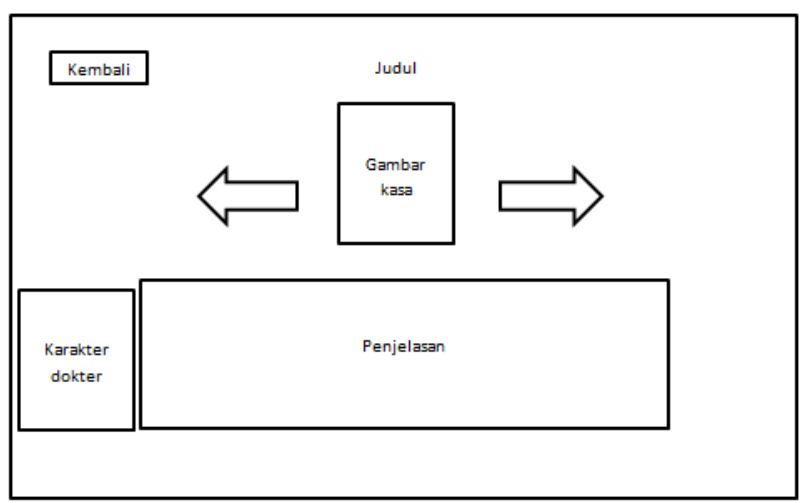

Gambar 6. Belajar Pengenalan Alat P3K

3. Rancangan Cara Bermain pada Edugame "P3KKids"

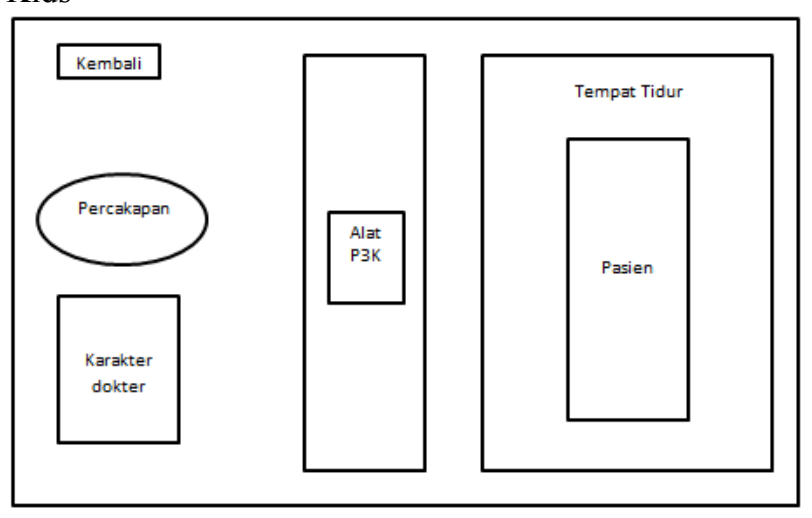

Gambar 7. Cara Bermain

4. Rancangan Bermain pada Edugame "P3K-Kids"

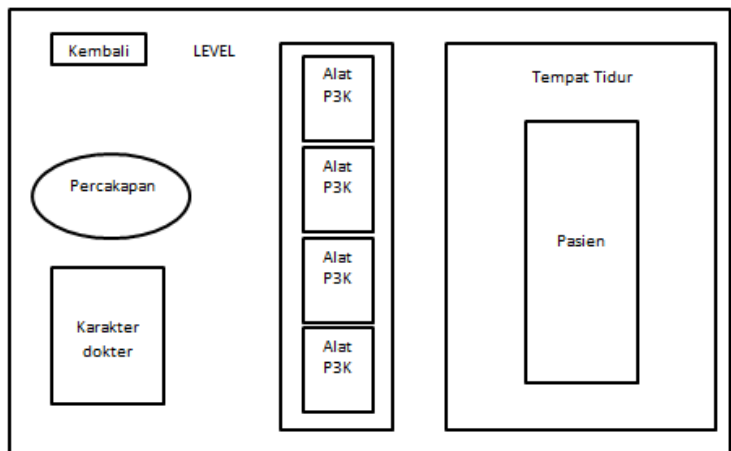

Gambar 8. Bermain

5. Rancangan Bermain pada Edugame "P3K-Kids"

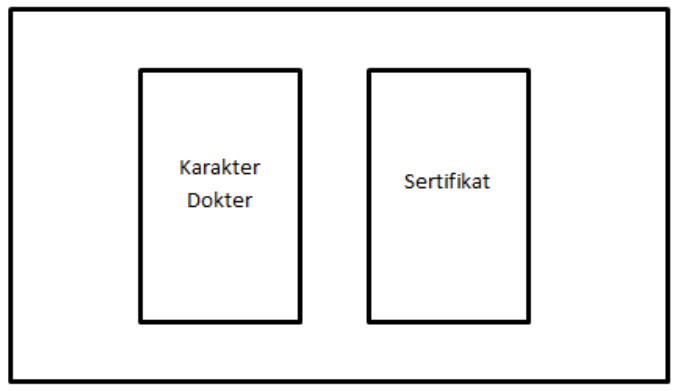

Gambar 9. Penghargaan

6. Use Case Diagram Edugame "P3K-Kids" dapat dilihat pada gambar 10, bahwa pemain dapat melakukan beberapa aksi sebelum memulai permainan. Dalam menu utama user dapat memilih button "Belajar" untuk menampilkan scene materi belajar, dimana dalam scene belajar terdapat scene pembelajaran tentang plaster, kasa, obat-obatan, antiseptik, kapas, alkohol, perban, kompres, mitella, sarung tangan, masker, gunting, pinset, dan lampu senter. Jika memilih button "Bermain" untuk memulai permainan.

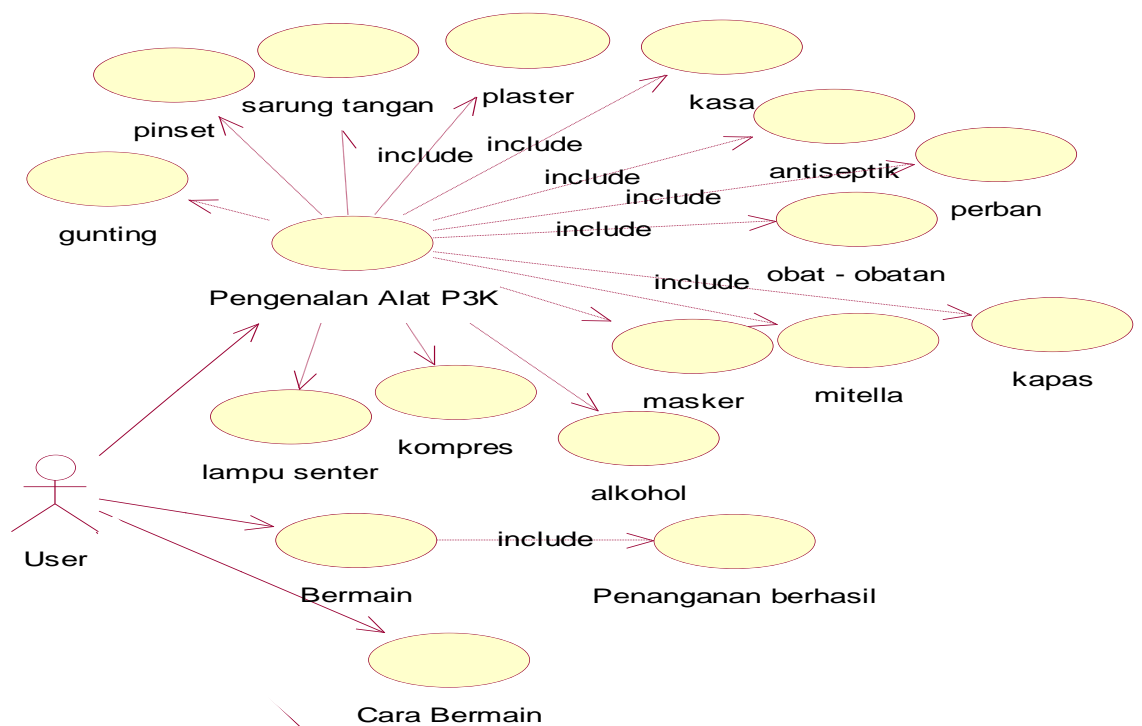

Gambar 10. Use Case Diagram 
7. Activity Case Diagram Edugame "P3K-Kids" dapat dilihat pada gambar 11, alur aktifitas yang terjadi disaat user memilih "Pengenalan Alat P3K" pada menu pilihan. Saat user memilih "Pengenalan Alat P3K", maka sistem akan langsung menampilkan scene "Pengenalan Alat P3K" dan kita dapat memilih materi apa saja yang kita ingin pelajari seperti pembelajaran tentang plaster, kasa, obat-obatan, antiseptik, kapas, alkohol, perban, kompres, mitella, sarung tangan, masker, gunting, pinset, dan lampu senter.

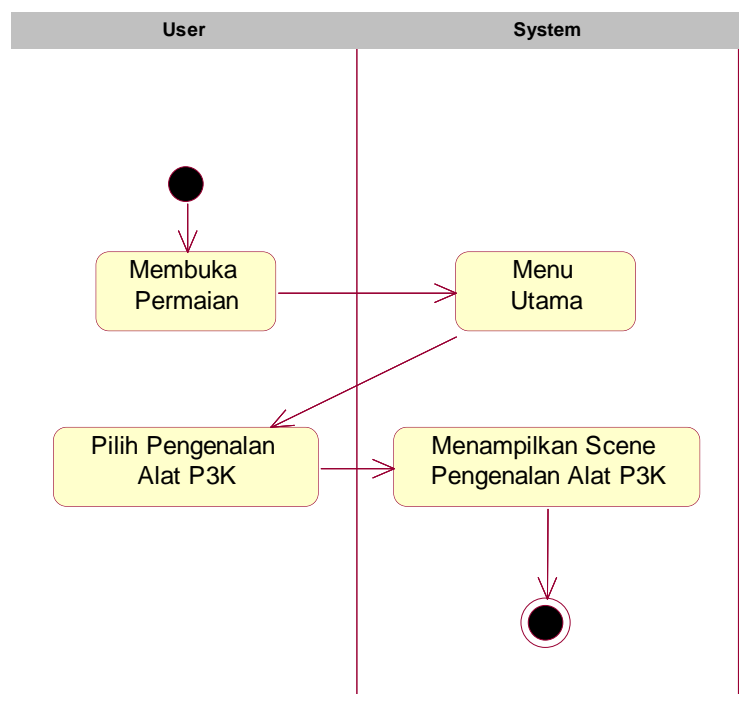

Gambar 11. Activity Diagram Pengenalan Alat P3K

8. Activity Diagram Edugame "P3K-Kids" dapat dilihat pada gambar 12, alur aktifitas yang terjadi disaat user memilih "Bermain" pada menu utama. Saat pemain memilih "Bermain", sistem akan langsung menampilkan scene "Bermain" untuk memulai permainan. Selanjutnya user memainkan permainan tersebut dengan cara memberikan pertolongan pada pasien yang mengalami cedera dengan alat P3K sesuai dengan cedera yang di alami oleh pasien. pasien tertolong maka akan berhasil dan ke level berikutnya.

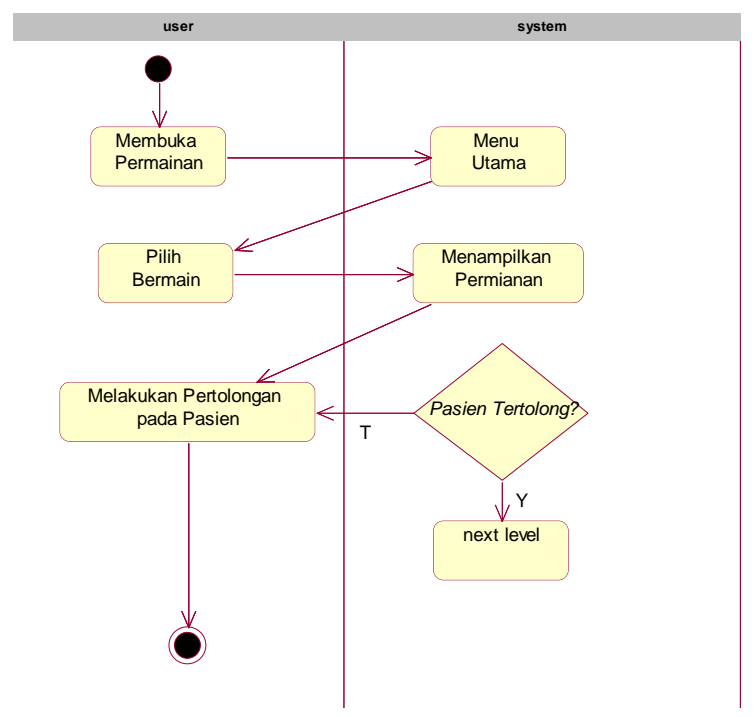

Gambar 12. Activity Diagram Bermain

9. Squence Diagram Edugame "P3K-Kids" menunjukkan proses yang terjadi antara user dengan sistem, Terlihat pada Sequence Diagram Edugame Pertolongan Pertama Pada Kecelakaan ini terlihat pemain masuk ke scene menu utama. Selanjutnya pemain memilih button (tombol) Pengenalan alat P3K pada menu utama dan disusul masuk ke scene Pengenalan Alat $\mathrm{P} 3 \mathrm{~K}$, pada scene ini pemain dapat mempelajari kegunaan alat $\mathrm{P} 3 \mathrm{~K}$ yang sebagian terdapat dalam Permainan, jika user memilih button bermain maka pemain akan memulai bermain dan menyelesaikan permainan.

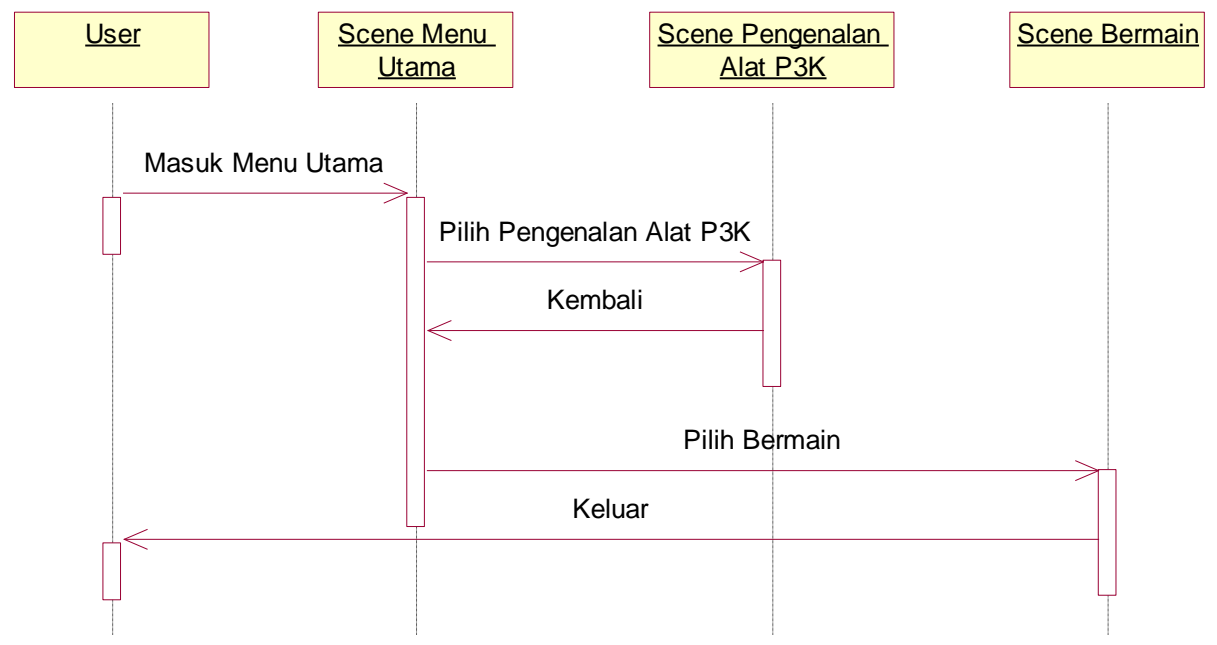

Gambar 13. Squence Diagram Edugame "P3K-Kids" 


\section{IMPLEMENTASI}

Hasil implementasi berdasarkan konsep dan perancangan adalah sebagai berikut :

1. Tampilan Menu Utama

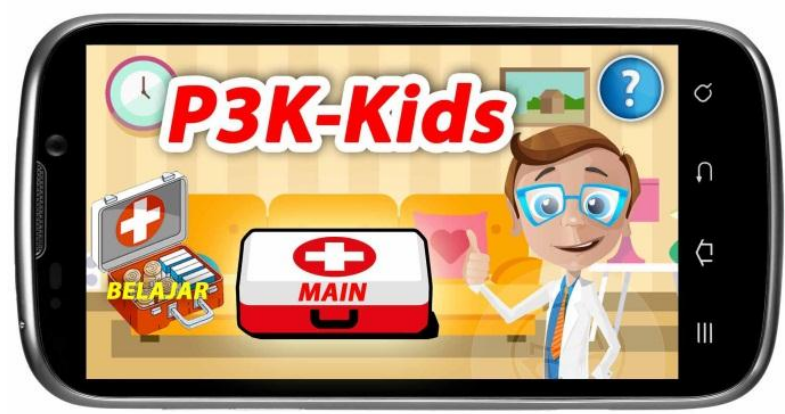

Gambar 13. Menu Awal

Seperti yang terlihat pada gambar 13, Pada tampilan menu utama ini terdapat 3 tombol yaitu "Belajar" untuk pengenalan alat P3K, "Main" untuk bermain, dan tombol tanda tanya untuk menampilkan tutorial cara bermain game ini.

2. Tampilan Belajar Alat P3K

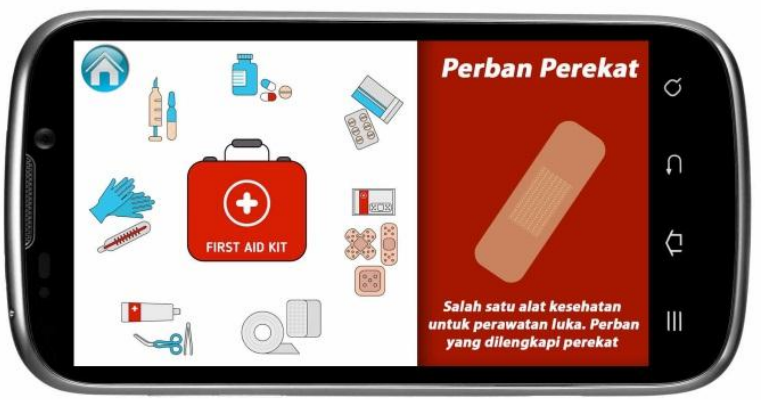

Gambar 14. Tampilan Pengenalan Alat P3K

Seperti yang terlihat pada gambar 14, Pada tampilan Belajar alat P3K ini terdapat beberapa menu alat P3K yang apabila ditekan akan menampilkan informasi cara menggunakannya.

3. Tampilan Bermain

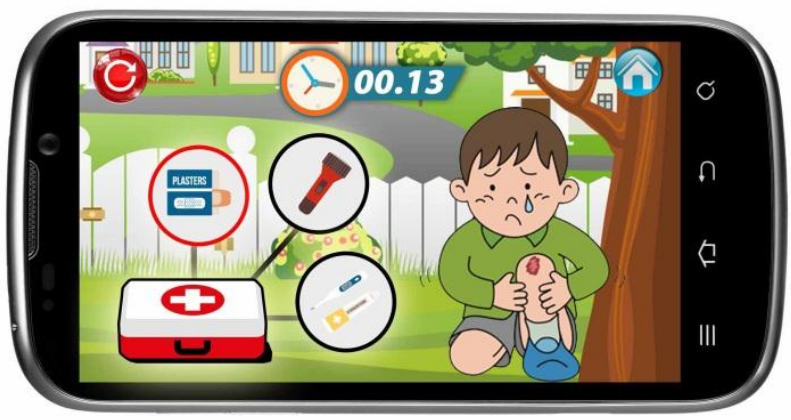

Gambar 15. Tampilan Bermain

Seperti yang terlihat pada gambar 15 , scene dimana user bermain dengan cara memberi pertolongan pertama pada pasien yang mengalami cedera sesuai dengan instruksi yang diberikan oleh dokter, pemain harus menyelesaikan lima level. Jika user telah menyelesaikan penanganan cedera pada pasien, maka user dapat lanjut ke level berikutnya. Apabila user telah menyelesaikan ke lima level tersebut, maka akan masuk ke scene penghargaan dan pemain dapat mengulang permainan dari level awal dengan masing - masing level yang telah di random dengan jumlah dan jenis penanganan dam cedera yang berbeda - beda agar permaianan tidak monoton. Terdapat waktu mundur (count down) disetiap levelnya, apabila user gagal menyembuhkan pasien saat waktu habis, maka permainan akan game over.

\section{Tampilan Cara Bermain}

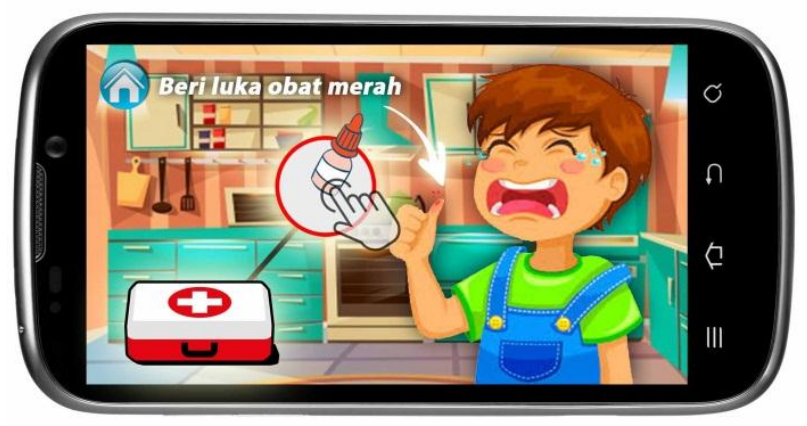

Gambar 16. Cara Bermain

Seperti yang terlihat pada gambar 16, Cara Bermain dimana pada scene cara bermain menampilkan animasi bergerak tentang cara bermain untuk melakukan pertolongan pertama pasien yang mengalami cedera. Scene ini akan tampil saat user menekan tombol tanda tanya di menu awal (gambar 13)

\section{Tampilan Penghargaan}

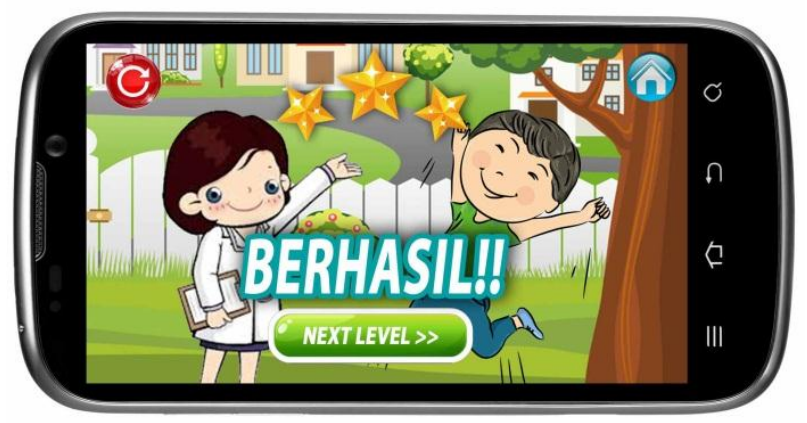

Gambar 17 . Penghargaan

Penghargaan (lihat gambar 17) adalah scene yang akan menampilkan penghargaan kepada user yang telah berhasil memberikan pertolongan pertama pada pasien yang mengalami cedera setiap level yang ada di permainan P3K. Scene ini terdapat 3 button yaitu button bermain lagi, button kembali ke menu utama, dan button ke level berikutnya (next level). 


\section{KESIMPULAN}

Konsep Edugame "P3K-Kids" adalah permainan atau game edukasi yang dapat memberikan pengetahuan di bidang kesehatan, tentang cara memberikan pertolongan pertama pada kecelakaan saat kita beraktivitas. Edugame Edugame yang dibangun khusus untuk mengenalkan P3K kepada anak melalui permainan.

Edugame ini menggunakan algoritma pengacakan posisi soal permainan atau bisa disebut shuffle random yang berfungsi untuk mengacak soal dengan tujuan agar pemain tidak dapat mengingat urutan soal dalam permainan.

\section{SARAN}

Berdasarkan hasil dari penelitian ini ada beberapa saran, yaitu, perlu adanya perbaikan maupun penambahan fitur sehingga game ini dapat terlihat lebih menarik. Permainan ini hanya berbasis game android, diharapkan ada pihak yang mampu mengembangkan menjadi berbasis platform lainya seperti $i O S$ dan lain lain.

\section{DAFTAR PUSTAKA}

Agarwal, B. B., Tayal, S. P., dan Gupta, M., 2010. Software Engineering and Testing, Burlington, USA: Jones \& Bartlett Learning.

Andrea, R. 2013. Teknik Pengacakan Posisi Objek "Find Me! - The Game. Prosiding Seminar Nasional Ilmu Komputer. 1 November 2013, Samarinda, Indonesia. Hal. 301-303.

Andrea, R. 2015. Teknik Pengacakan Posisi Objek Permainan Match-up "Find Me!-Bumi Etam". Semnasteknomedia online, 3(1), 5-7.

Chee, K. N., Yahaya, N., \& Ibrahim, N. H. 2018. Factors of students' performance based on cognitive level in a mobile learning environment. International Journal of Mobile Learning and Organisation, 12(2), 190-212.

Ekaprasetia, F., Kristianto, H., \& Susanto, T. 2018. First Aid Guideline (FAG): A first aid education application for children aged 11-14 years in Indonesia. Journal of Taibah University Medical Sciences.
Hurd, D dan Jenuings, E. 2009. Standardized Educational Games Ratings: Suggested Criteria. Longman. London.

Kristanto, N., Maliya, A., \& Hudiyawati, D. 2016. Efektivitas Pendidikan Kesehatan Terhadap Perubahan Pengetahuan Dan Keterampilan P3k Pada Siswa Pmr Di SMA Negeri 3 Sukoharjo (Doctoral dissertation, Universitas Muhammadiyah Surakarta).

Liu, W., Cao, L. H., \& Jie, L. I. 2017. Development And Application Of New Type Of Individual First Aid Kit For Plateau Soldiers. Chinese Medical Equipment Journal, 38(9), 23-25.

Squire, K. 2011.Video Games and Learning: Teaching and Participatory Culture in the Digital Age. Technology, Education--Connections (the TEC Series). Teachers College Press. 1234 Amsterdam Avenue, New York, NY 10027.

Vos, N., Van Der Meijden, H., \& Denessen, E. 2018. Effects of constructing versus playing an educational game on student motivation and deep learning strategy use. Computers \& Education, 56(1), 127-137. 2011. Alsubaie, A., Alaithan, M., Boubaid, M., \& Zaman, N. Making learning fun: Educational concepts \& logics through game. In Advanced Communication Technology (ICACT), 2018 20th International Conference on (pp. 454459). IEEE.

Yusnita, A., Wijayanti, S., \& Felita, P. A. 2017. Implementasi Algoritma Shuffle Random Pada Edugame Magic Time berbasis Universal Windows Platform (uwp). In Prosiding Seminar Poltekba (vol. 2, no. 1).

\section{UCAPAN TERIMA KASIH}

Publikasi ini dibiayai oleh:

Direktorat Riset dan Pengabdian Masyarakat

Direktorat Jenderal Penguatan Riset dan Pengembangan Kementerian Riset, Teknologi, dan Pendidikan Tinggi sesuai dengan Kontrak Penelitian Tahun Anggaran 2019 